\title{
Uma política da narratividade: \\ experimentação e cuidado nos relatos dos redutores de danos de Salvador, Brasil
}

\author{
Rafael Mendonça Dias (a) \\ Eduardo Passos ${ }^{(b)}$ \\ Marco Manso Cerqueira Silva ${ }^{(c)}$
}

Dias RM, Passos E, Silva MMC. A politic of narratives: experimentation and care in the reports by agents of harm reduction in Salvador, Brazil. Interface (Botucatu). 2016; 20(58): 549-58.

This paper investigates the politic of narratives featured in field reports conducted by agents in a Harm Reduction Program of Salvador (Brazil) in 2012. The research had a starting point in the field diaries to then analyze which narrative strategies are originated in the daily routine of Harm Reduction (HR) in the context of the Brazilian public health. The exploration of these narrative strategies reveals an unique experience of care with drug users in the streets. This experience also encompasses the care given to the experience of field work and research itself. As a consequence emerges in the narratives of the agents a link between experimentation and care.

Keywords: Harm reduction. Mental health. Narratives. Experimentation. Care.
O presente artigo investiga a política da narratividade vigente no relato das experiências de campo realizadas por redutores de danos de um Programa de Redução de Danos (PRD) de Salvador, Brasil, em 2012. Partimos dos diários de campo dos agentes redutores de danos para analisar quais são as estratégias narrativas engendradas no cotidiano das práticas da RD no campo da saúde pública brasileira. A apreciação das narrativas revela uma singular experiência de cuidado com os usuários de substâncias psicoativas nas ruas da cidade, que se desdobra no cuidado com a própria experiência de campo e de pesquisa. Dessa forma, emerge nas narrativas dos redutores de danos uma articulação entre experimentação e cuidado.

Palavras-chave: Redução de dano. Saúde mental. Narrativas. Experimentação. Cuidado.

\footnotetext{
(a) Departamento de Psicologia, Universidade Federal Fluminense/ Volta Redonda. Volta Redonda, RJ, Brasil. Rua Desembargador Ellis Hermydio Figueira, Aterrado. Volta Redonda, RJ, Brasil. 27213-145. rafaeldias@id.uff.br (b) Instituto de Psicologia, UFF/Niterói. Niterói, RJ, Brasil. e.passos@ superig.com.br

(c) Aliança de Redução de Danos, Faculdade de Medicina da Bahia, Universidade Federal da Bahia (FAMEB/ UFBA). Salvador, BA, Brasil.marcomansso@ gmail.com
} 


\section{Introdução}

Os diários de campo constituem uma ferramenta de registro e análise do trabalho dos agentes redutores de danos. Os relatos aqui apresentados expressam o trabalho de campo desenvolvido pela Aliança de Redução de Danos - Fátima Cavalcanti (ARD-FC), Serviço de Extensão Permanente da Faculdade de Medicina da Universidade Federal da Bahia (UFBA) em parceria com o Centro de Atenção Psicossocial de Álcool e outras Drogas (CAPSad) Gregório de Matos.

Os relatos dos redutores de danos, disponibilizados pela ARD-FC, documentam as experiências vividas durante o trabalho realizado no centro histórico de Salvador. Nesse artigo, analisamos dez diários de campo escritos pelos redutores de danos no ano de 2012. A análise do material foi feita tendo como foco o mapeamento de uma política da narratividade construída na experiência de cuidado com as pessoas que fazem uso de drogas.

$\mathrm{Na}$ ARD-FC, os relatos de campo são apresentados nas práticas de supervisão institucional. Essas narrativas, de modo mais amplo, registram a memória das estratégias de Redução de Danos (RD) no Brasil.

A metodologia da RD influenciou experiências participativas com a juventude de bairros populares com elevados índices de homicídios e violência policial em Salvador ${ }^{1}$ e no Rio de Janeiro ${ }^{2}$.

A história da RD no Brasil passou por três períodos: o primeiro iniciou-se em 1989, em Santos; o segundo em 1994, por meio do Programa Nacional (PN) - DST/aids; e o terceiro em 2003, quando a RD surgiu, como um método clínico-político e um paradigma da Política do Ministério da Saúde de Atenção Integral para Usuários de Álcool e outras Drogas 3 .

As primeiras práticas da RD no Brasil estão ligadas às experimentações das políticas públicas de saúde realizadas na cidade de Santos, em 1989, baseadas nas diretrizes do Sistema Único de Saúde (SUS), e à adoção de práticas de prevenção entre usuários de drogas injetáveis (UDI) daquela cidade.

Em 1994, o "Projeto Drogas" da PN-DST/aids foi realizado no Brasil com o apoio da Organização das Nações Unidas. Suas principais iniciativas foram os Programas de Redução de Danos (PRDs), implantados, inicialmente, em dez estados brasileiros.

Em 2003, com a Política de Atenção Integral para Usuários de Álcool e outras Drogas do Ministério da Saúde, a RD passou a se consolidar como o paradigma das políticas públicas para álcool e outras drogas no Brasil, em contraste com o paradigma da "guerra às drogas"4. Em 2005, são editadas as Portarias (n० 1.028 e 1.059) do MS que tratam da regulamentação da RD no SUS e o seu incentivo no Centro de Atenção Psicossocial para Álcool e outras drogas (CAPSad) ${ }^{5}$. Inicia-se, então, uma maior articulação com os dispositivos de saúde mental e a atenção básica. Em 2006, a Lei no 11.343 instituiu um novo marco legal para as políticas sobre drogas no país, mas não alterou o sistema proibicionista ${ }^{6}$.

$A R D$ vai paulatinamente deixando de ser uma medida exclusivamente de prevenção às DST/aids e torna-se um paradigma para a política de drogas, que teve o seu campo de intervenção ampliado devido à participação direta das pessoas que fazem uso de drogas nas práticas de gestão e atenção ${ }^{7}$. Atualmente, o paradigma da RD se apresenta como uma concepção do cuidado integral ${ }^{8}$. Essa ampliação segue hoje com a articulação das estratégias de RD com outros dispositivos.

A consolidação da RD como paradigma da política de drogas é inseparável da ampliação da perspectiva de cuidado, com a participação ativa das pessoas que fazem uso de drogas e dos seus processos de subjetivação.

Os modos de gestão e atenção são indissociáveis para o paradigma da RD. A função de gestão é concebida em uma visão de compartilhamento. Por outro lado, a prática de cuidado é entendida e experimentada a partir da lateralidade da experiência dos sujeitos implicados no processo de produção de saúde, ampliando o sentido da clínica9. Tal prática desenvolve um "olhar de dentro" da experiência com as drogas ${ }^{10}$ que se coloca ao lado do cuidado, frente ao cenário deflagrado pela guerra às drogas e sua linha totalitária.

A gestão do cuidado ${ }^{11,12}$ e a cogestão dos coletivos ${ }^{13}$ são propostas com que o paradigma da RD filia-se para romper com as práticas de saúde baseadas na gestão dos riscos ${ }^{14}$. $A R D$, na sua prática clínico-política, vai além da racionalidade epidemiológica e contrasta com os modos de governo 
do corpo e das populações "vulneráveis" e sua gestão administrativa, uma tecnologia política que Foucault ${ }^{15}$ denominou de biopoder.

Para a discussão que realizamos neste artigo, além dos diários dos redutores de danos, utilizaremos o diário de campo de pesquisa realizada por nós em 2012.

\section{Narrativas de campo como cartografias da experiência}

René Lourau ${ }^{16}$ considera que os diários de pesquisa revelam aquilo que está "fora do texto" das publicações científicas, o que é considerado marginal na experiência acadêmica. Esse "fora do texto" expõe a implicação do pesquisador, pois "falam sobre a vivência de campo cotidiana e mostram como, realmente, se faz pesquisa"16 (p. 74).

Para Lourau17, a análise das implicações do pesquisador com o campo é um caminho fértil para investigar os pertencimentos e as referências institucionais que comparecem na experiência de pesquisa. Tal análise retoma aquilo que é experimentado e comporta certa dose de perigo na travessia de determinado território existencial ${ }^{18}$.

Os relatos de campo aqui analisados apresentam uma cartografia das práticas de cuidado com usuários de drogas, nas quais estão imbricadas a produção de saúde e a produção de subjetividade.

Escóssia e Tedes $\mathrm{Co}^{19}$ afirmam que o método da cartografia visa analisar o plano coletivo das forças envolvido na dimensão processual da realidade, ampliando a perspectiva de análise. O método cartográfico pressupõe que o ato de investigar intervém sobre a realidade investigada na forma da pesquisa-intervenção, e requer a habitação de um território para traçar um plano comum, que coloca lado a lado aquele que conhece e aquele que é conhecido ${ }^{20,21}$.

Os modos de narrar a experiência na pesquisa em saúde têm implicações políticas, uma vez que definem perspectivas sobre o mundo e si mesmo ${ }^{22}$. Por outro lado, o problema da narratividade envolve tanto dimensão política quanto estética, já que as formas de intervenção nos sentidos da realidade pressupõem o que o filósofo Jacques $\operatorname{Rancière~}^{23}$ (p. 15) definiu como partilha do sensível, isto é, "o sistema de evidências sensíveis que revela, ao mesmo tempo, a existência de um comum e dos recortes que nele definem lugares e partes respectivas".

É a partir desse comum em partilha que as experiências política e estética se articulam. A experiência narrativa expressa um modo de tomar parte nas relações do campo analisado, onde se atravessam políticas de saúde, políticas de drogas e políticas da subjetividade.

As pesquisas qualitativas em saúde têm se interessado na utilização de narrativas como ferramenta metodológica ${ }^{24}$ e que servem para acessar a experiência compartilhada ${ }^{25,26}$. A análise de narrativas e a produção de dispositivos coletivos são ferramentas cada vez mais presentes no campo da saúde mental para lidar com os desafios atuais da atenção psicossocial.

Esse é o caso, por exemplo, da pesquisa-intervenção em saúde mental realizada com a diretriz da Gestão Autônoma da Medicação (GAM) a partir da experiência do uso de psicofármacos nos CAPS. A produção de narrativas dos usuários de psicofármacos e a gestão compartilhada com familiares, trabalhadores de saúde e gestores propiciaram a oportunidade, mais ampla, de avaliar as práticas de cuidado em saúde mental27-29.

Nos diários de campo dos redutores de danos podemos ver, também, que a prática de cuidado emerge na experiência narrativa que Walter Benjamim ${ }^{30}$ designa como a dignidade de contar sua vida de maneira inteira.

\section{O centro histórico, a rua e o CAPSad}

As narrativas analisadas evidenciam a articulação do trabalho de campo e práticas de cuidado no centro histórico da cidade ${ }^{31}$. A ação no território da ARD-FC está integrado ao CAPSad Gregório de Matos e sua área de atuação.

Em 26 de julho de 2012, o redutor de danos descreve o contato com a comunidade tradicional da Gamboa, que fica ao lado do Solar do Unhão e perto dos prédios de classe média do Campo Grande, 
centro de Salvador. Ele tece a cartografia da cidade sob a ótica da experiência de cuidado: "A comunidade da Gamboa, muito conhecida pelo seu local privilegiado em frente à baía de Todos os Santos, é habitada em grande maioria por pessoas sem acesso adequado à moradia, lazer e cultura".

O narrador é sensível às desigualdades sociais que permeiam e constituem o mapa da cidade, se deparando com uma ação da polícia civil no local:

"Com suas armas em punho, os quatro policias civis desceram a Gamboa à procura de mais uma vítima para se colocar na conta do Estado. Percebemos o clima de insatisfação por parte de alguns catadores que trabalham na cooperativa de recicláveis e decidimos então fazer um breve roteiro e voltarmos para a faculdade de medicina, já que o campo hoje se encontrava muito tenso devido a tais visitas extras".

O relato é irônico ao discutir a presença da polícia e a possibilidade de haver mais uma vítima do Estado; a ação da polícia é uma visita esperada que constrange as ações de cuidado no campo. Na chegada da polícia, há a saída do redutor de danos, havendo uma incompatibilidade entre as duas ações. O cuidar e o controlar se fazem em direções opostas, a presença de um impedindo a do outro. O mapa da cidade se compõe das linhas duras dos autoritarismos e das linhas que fogem por meio de estratégias de resistências, muitas vezes, perigosas. O redutor está em meio a esta cartografia enquanto a traça.

No relato do dia 31 de julho de 2012, outro redutor de danos começa avaliando a situação do centro histórico de Salvador, perto da rua $28 \mathrm{de}$ Setembro.

"As ruas do centro histórico estão bastante deterioradas por conta do descaso da ordem pública, neste momento o Pelourinho está em reforma e os grandes casarões antigos estão repletos de trabalhadores da construção civil. Seus prédios e monumentos têm paredes nuas e rachadas e suas ruas estão repletas de entulho e lama".

O redutor de danos nos pinta uma cena em cores fortes. A paisagem é apresentada de maneira a compartilhar com o leitor sua impressão ao habitar o território. O relato segue descrevendo um contato com uma pessoa atendida que, pela singularidade do seu caso, valeria ter sua história projetada nas telas de cinema. O personagem não se enquadra em um estereótipo do usuário de drogas. A figura estereotipada do "crakudo"(d) não corresponde à narrativa que acompanha a singularidade de uma vida. Sim, há uma vida na experiência do usuário de crack.

“Também neste dia encontramos um usuário de crack muito engraçado [...], que fuma apenas 1 ou 2 pedras por dia, durante a noite, para não ficar viciado, falou-nos de como utilizava o crack antes de fazer relações sexuais, mas que, porém, preferia fumar maconha, inclusive nos contou suas desventuras com o uso de cocaína, algo que valeria uma produção cinematográfica com certeza".

Ocorre um contato dos redutores de danos com operários da construção civil que trabalham na reforma do centro histórico, na região do Gravatá. O relato apresenta o cenário:

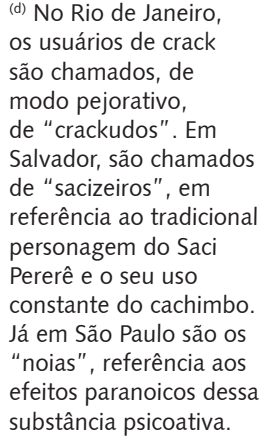

(d) No Rio de Janeiro, os usuários de crack são chamados, de modo pejorativo, de "crackudos". Em Salvador, são chamados de "sacizeiros", em referência ao tradicional personagem do Saci Pererê e o seu uso constante do cachimbo. Já em São Paulo são os "noias", referência aos efeitos paranoicos dessa substância psicoativa. 
“Passamos pela Rua 28 [de Setembro], como de costume entregamos muitos preservativos aos trabalhadores da construção civil que estão trabalhando na reforma dos casarões. Este tem sido um público bastante receptivo ao nosso trabalho; chegaram a nos convidar para falarmos sobre o uso de drogas com todos os colegas [...]".

Nessa rua, existe uma cena de uso de crack, e os operários da reforma trabalham no mesmo espaço. O narrador anota: " [...] a relação dos trabalhadores com os usuários de crack parece ser amistosa". A paisagem ganha a complexidade própria da cidade, onde se distinguem sem se separar personagens de histórias distintas. O operário e o usuário de crack podem ficar lado a lado porque a vida pública não é homogênea.

O redutor de danos toma a complexidade da cidade como matéria de seu trabalho. No lugar de julgar, acolhe esta diferença e negocia com ela. Certamente, nem todos são igualmente diferentes, pois a presença da força policial confere à cidade um tom grave e judicativo. Talvez não seja possível ser diferente, mas coloca-se, para a RD, o desafio de pensar as políticas públicas de saúde negociando com as diferentes experiências. Os agentes redutores de danos mostram, no relato, a mobilidade dos usuários de crack atendidos pelo projeto, de acordo com a presença da polícia militar no território:

"O número de usuários de crack tem reduzido bastante; nas últimas semanas não têm passado de 05, o oposto do Gravatá que alterna bastante. Temos percebido que, de três visitas que fizemos, em duas havia presença de PM nas adjacências e em uma outra não havia nenhum policial. Neste dia, o número de usuários fazendo uso nas ruas subiu consideravelmente, além de presenciarmos cenas de tráfico intenso".

Os matizes da paisagem complexa da cidade não contrastam apenas usuários e força policial. $\mathrm{Na}$ verdade, parte da sociedade se sente representada na ação repressora da polícia. O uso de drogas tem uma representação social negativa e o usuário, muitas vezes, se vê frente à avaliação do outro, necessitando de alguém que facilite a mediação.

A narrativa do redutor descreve ainda um acontecimento no centro histórico de Salvador: o encontro com uma pessoa que recebe cuidados no Centro de Atenção Psicossocial de Álcool e outras drogas (CAPSad) Gregório de Matos e seu pedido para que eles interviessem junto a seu chefe e colegas no trabalho, que não o compreendiam.

“Hoje, quando nos aproximávamos do Gravatá, fomos abordados por um usuário do CAPS que pediu nossa ajuda para conversarmos com seu chefe no seu trabalho. Ele parecia estar bastante emocionado por se sentir não compreendido por seus colegas de trabalho. Apesar de estar de licença do trabalho, ele vem visitando o local frequentemente. Chorou várias vezes, ao falar do seu internamento em uma CT (comunidade terapêutica)[...]".

No momento do relato, o usuário está sendo acompanhado pelo CAPS, mas já passou por internação em comunidades terapêuticas. Os redutores, de acordo com a solicitação, se deslocam até o trabalho dele. O narrador observa: "Percebi um sofrimento do usuário ao se declarar um 'dependente' e 'doente' e dizia não ter culpa de estar assim".

No contato do redutor de danos com o CAPSad, verificamos a importância dessa função de mediação, uma vez que o cuidado ganha aqui o sentido de negociação e manejo. O redutor se posiciona entre realidades, trabalhando pela ampliação da abertura comunicacional entre o usuário de drogas e outros setores da sociedade, aí incluídos os próprios trabalhadores de saúde, como é o caso dos profissionais do CAPSad. É indispensável, ao redutor, colocar em questão as crenças estabelecidas, não só nos trabalhadores de saúde como, também, nos usuários de drogas.

O paradigma biomédico aparece no discurso do usuário de droga que se considera um "dependente" e "doente". No entanto, na experiência de cuidado, se possibilita a criação de outros sentidos para o sofrimento. Quando o redutor narra a situação vivida, ele sublinha os termos empregados para descrever a experiência com as drogas, estranhando o sentido naturalizado. 
No mesmo cenário do centro histórico de Salvador, é exposto o trabalho de campo na Rua 28 de Setembro e no Gravatá. "Foi um dia de campo dos bons". Os redutores de danos notam o aumento da demanda por preservativos na sexta-feira. O relato enfatiza que o movimento estava intenso e que muitas pessoas paravam para ouvir o que os redutores tinham para dizer.

$\mathrm{Na}$ narrativa desse trabalho de campo, lemos a conversa que o redutor teve com uma pessoa em situação de rua. Ele comenta sobre esse encontro:

"[...] o que mais me marcou nesse campo foi a longa conversa que eu tive com [...] um morador de rua e usuário de crack e álcool, que me contou sua história de vida. Ele descreveu as coisas que determinaram a situação atual dele; falou muito de um filho que cuidou com muito esforço até os seis anos de idade e depois, em decorrência de um relacionamento problemático e já sem o apoio da família, terminou por tornar-se usuário de crack e posteriormente morador de rua. Em vários momentos do diálogo ele se emocionou, chorou bastante; me vi num papel importante de acolher e fazer uma escuta que proporcionasse a catarse dele".

Esse relato, assim como aparece em outros, indica a possibilidade de o usuário narrar sua própria experiência. O redutor descreve seu estímulo à narrativa do usuário e, neste exponencial narrativo, deparamo-nos com uma direção do cuidado: cuidamos quando damos sentido à narrativa do outro, a legitimamos quando damos ouvidos a ela. A experiência do cuidado dá passagem a histórias que bifurcam, ganhando consistência vital onde não parecia haver saída. Em alguns casos, há o perigo de tudo desabar, como podia acontecer com os casarios do Pelourinho. A descrição do cenário de restauração do centro histórico pelos redutores de danos nos apresenta a possibilidade de restaurar, também, relações de cuidado, onde as drogas aparecem como um componente a mais nessa cartografia.

No curso desse contato, surge a descrença do usuário no tratamento no CAPSad. "Ao longo da conversa eu tentei por vezes inspirá-lo a vir ao CAPSad, iniciar um tratamento e um acompanhamento, já que ele relatou ter interesse em parar de usar, porém ele sempre se mostrava descrente no tratamento devido à sua condição de vida".

O relato marca a gratidão que foi gerada no encontro e as estratégias de vida e trabalho. A princípio, é o usuário que está grato frente à disponibilidade do trabalhador de saúde: "Ele em diversos momentos mostrou-se muito grato pela atenção e pela humildade em estar lá com ele". Mas a gratidão é, por definição, recíproca, já que o sucesso na prática de cuidado afeta a todos implicados na produção de saúde. Afetar e ser afetado são faces de uma mesma experiência entre redutor e usuários de drogas. O redutor de danos termina sua narrativa em primeira pessoa, destacando sua implicação e a "vontade imensa" que surgiu nesse campo de experiências com o outro.

“Eu fiquei com uma vontade imensa de ajudar este homem. Penso que tudo o que eu mais quero nesse campo é reencontrar [...] e despertar nele interesse em iniciar um tratamento no CAPSad, se fosse possível eu mesmo gostaria de fazer acompanhamento psicológico dele".

A possibilidade de o redutor de danos fazer o acompanhamento psicológico no CAPSad indica a consistência de uma linha de cuidado que abrange o território e os diferentes dispositivos.

O relato de 06 de novembro de 2012 aponta um acontecimento que envolve a ação de um policial na Rua 28 de Setembro. O policial, tentando estacionar, joga o carro em cima de uma redutora de danos e da pessoa que ela atendia. Diante da situação, o narrador reflete sobre sua impotência e silêncio diante da violência de um agente do Estado.

“Estávamos na 28 [de Setembro] quando um fato retirou minha atenção, e dos meus companheiros, onde um policial, na ânsia neurótica de estacionar seu carro no passeio, não teve trato algum com nossa colega redutora e a uma mulher que recebia um atendimento. Não posso negar que tive que controlar um ímpeto raivoso para não entrar na ação de protesto, 
pois a ele, policial, foi dado pelo Estado o poder do uso da violência, e diante disso meu único recurso de protesto foi o silêncio. As pedras falam, eu me calo".

A violência policial autorizada pelo Estado tem como contrapartida o protesto silencioso. O silêncio, no entanto, não pactua com a violência que vira material de análise na narrativa de uma situaçãolimite. O redutor se cala, mas entende que as pedras do calçamento da cidade guardam a narrativa da violência. Há uma memória política da cidade; há uma linguagem em surdina das ruas, que o redutor aprende a ouvir.

No mesmo relato, o redutor de danos reflete sobre sua posição no campo e faz análise da relação com o "outro a quem pretendemos cuidar".

“Desde já, pude me deparar com um sentimento comum no trabalho com o território que o Redutor precisa lidar, a saber: a impotência. Trabalhamos com nossos limites, no limiar do desejo do outro a que pretendemos cuidar, formar vínculo, mobilizar para a própria condição. Lidamos com o nosso próprio desejo de implicação, de transformação, por isso, ao que já me parece, resiliência às frustrações é essencial".

A prática do cuidado é uma experiência-limite onde está em jogo a violência do Estado. No limiar das forças, com o corpo esgotado pela exigência do trabalho nas ruas, o encontro com a violência faz o redutor de danos colocar em xeque a possibilidade de intervenção sobre a realidade. Seu trabalho se realiza no limite da vida e da morte, lá onde experimenta sua alteridade como agente de saúde e a alteridade daquele que demanda cuidado.

As narrativas dão passagem para as histórias de vida no encontro com o outro no contexto da rua:

“Nesse dia, houve também escuta de histórias, inclusive de um senhor que se encontrava catando lixo em um balde. Ele contou a história de todos os seus filhos e netos, sua luta diária pela sobrevivência, revelando muita honestidade de um homem trabalhador, sua fala aparentava um homem sedento de escuta, pois não parava de falar por um bom tempo".

A experiência de cuidado abre a possibilidade de escuta das histórias simples que aparecem no caminho. O paradigma da RD se concretiza nessas práticas de cuidado em que os elementos éticos, estéticos e políticos ganham consistência crítica a partir da práxis. Multiplicidade de contatos que surgem no campo e os desafios em sustentar a posição ética do cuidado e da escuta. A história da cidade se enlaça com as histórias contadas pelos seus habitantes, pessoas simples que narram suas existências singulares.

Outro narrador analisa as transformações operadas pela mudança dos moradores de Pilar, localizada no centro histórico de Salvador. Os moradores serão removidos dessa localidade para um conjunto habitacional. Ele escreve:

"O local estava passando por um processo onde os moradores estavam se mudando para o novo conjunto habitacional instalado na localidade. Muitos barracos abandonados e destruídos e outros em processo de remoção. Por conta desse evento muitas pessoas estavam na rua e dentro do próprio conjunto fazendo justamente a transição de morada".

Também observa a condição de insalubridade do lugar, com o lixo jogado no chão e a degradação por que passa todo o ambiente. Ele relata: "A ladeira pela qual iniciamos o campo é bastante insalubre. Muito lixo, coisas jogadas no chão [...]". Ele vai compondo um quadro do Pilar com seu "terreno acidentado" e os "casarões que estão por cair".

A circulação das pessoas nessa localidade não é a mais adequada, mas, muitos deles, acostumados com as condições, já desenvolveram suas estratégias para enfrentar as adversidades: "Para as pessoas, as condições de circulação não são as melhores. Há momentos na ladeira que podem nos fazer escorregar, mas os moradores já têm as manhas." As "manhas" vêm da experiência em transitar por 
aquele território. É, ao mesmo tempo, uma malícia, técnica e esperteza adquiridas. Para andar nesse terreno, é preciso saber onde se pisa.

Os relatos aqui apresentados contam um pouco da trajetória da RD no Brasil. Mesmo que a paisagem esteja restrita à cidade de Salvador, podemos ver as linhas de força que constituíram a RD e que fizeram que ela ganhasse o estatuto de paradigma das políticas públicas sobre álcool e outras drogas.

As cenas descritas confirmam o objetivo do redutor de danos no trabalho de campo: entender o contexto em que as drogas se inserem ao invés de focar em uma causalidade linear entre o sujeito e a droga. A metodologia cartográfica, com o recurso dos diários de campo, ajuda a perceber as forças que se fazem presentes na prática de campo, aí incluídas as implicações do próprio redutor, que produz e colhe narrativas. O diário de campo mapeia o campo de intervenção e serve de análise da experiência.

\section{Conclusão}

A partir da apreciação dos relatos de campo, entendemos que o paradigma da RD orienta uma experiência de cuidado que evidencia a inseparabilidade entre as práticas de atenção e as de gestão do processo de trabalho na rede de dispositivos de saúde. O cuidado do outro, o cuidado de si e da cidade se apresentam, também, como faces indissociáveis do trabalho com pessoas que fazem uso abusivo de drogas.

A prática do cuidado é, dessa maneira, uma experimentação clínico-política que resiste ao ideal preventivo baseado nas noções de periculosidade e de população de risco. No lugar de tomar o usuário de drogas como um perigo e risco social, as práticas de RD descritas constroem um plano de contato com o outro, acolhendo-o em sua diversidade, para avaliar e negociar com ele a redução dos danos psicossociais que estão associados ao uso abusivo de drogas. Por isso, estamos falando de um processo de produção compartilhada da experiência e de cogestão dos coletivos ${ }^{13}$.

As narrativas dos redutores de danos localizam-se nesse espaço intersticial entre a experiência de cuidado de si e o cuidado com a experiência dos usuários de substâncias psicoativas no contexto da rua. Tal complexidade da prática do cuidado articula a proposta da RD com os movimentos sociais que dão consistência a esse campo de problematização do uso e abuso das drogas.

O cuidado da experiência se define como abertura às produções subjetivas singulares. Valoriza-se a experiência dos usuários de drogas, seus saberes e práticas, e legitima-se a experimentação dos agentes redutores de danos como caminho ético para a prática de cuidado.

\section{Colaboradores}

Os autores participaram, igualmente, de todas as etapas de elaboração do artigo.

\section{Referências}

1. Espinheira G, organizador. Sociedade do medo: teoria e método da análise sociológica em bairros populares de Salvador: juventude, pobreza e violência. Salvador: Edufba; 2008.

2. Rodriguez A. A rede Rotas: desafios e possibilidades do trabalho em rede. In: Fernandes F, organizador. Redes de valorização da vida. Rio de Janeiro: Observatório de Favelas; 2009. 
3. Ministério da Saúde (BR). Secretaria Executiva, Coordenação Nacional de DST e Aids. A Política do Ministério da Saúde para atenção integral a usuários de álcool e outras drogas. Brasília (DF): Ministério da Saúde; 2003.

4. Barros R, Passos E. Afinal, é possível uma outra política de drogas para o Brasil? In: Lima E, Ferreira Neto JL, Aragon LE, organizadores. Subjetividade contemporânea: desafios teóricos e metodológicos. Curitiba: CRV; 2010. p. 61-70.

5. Dias R. Do asilo ao CAPSad: lutas na saúde, biopoder e redução de danos [dissertação]. Niterói (RJ): Universidade Federal Fluminense; 2008.

6. Carvalho S. A política criminal de drogas no Brasil: estudo criminológico e dogmático da Lei 11.343/06. 6a ed. São Paulo: Saraiva; 2013.

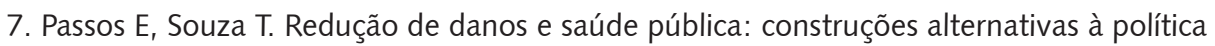
global de "guerra às drogas". Psicol Soc. 2011; 23(1):154-62.

8. Andrade T. Abre aspas. Jornal A Tarde. Salvador. 25 Nov 2012. 243.

9. Cunha AG. Dicionário etimológico Nova Fronteira da língua portuguesa. Rio de Janeiro: Nova Fronteira; 1982.

10. Medeiros $M$, Formaggini B, Manso $M$. Retrato favela: um olhar de dentro [vídeo]. Brasília (DF): Ministério da Saúde, DST/aids e Associação Bahiana de Redução de danos (ABAREDA); 2003.

11. Cecilio LCO. Innovating when producing health care, practices, and knowledge: how to avoid doing "ever the same". Saude Soc. 2012; 21(2):280-9.

12. Merhy E. O ato de cuidar: a alma dos serviços de saúde? [Internet]. Campinas; 1999 [acesso 2015 jan 15]. Disponível em: http://www.uff.br/saudecoletiva/professores/ merhy/artigos-05.pdf

13. Campos GWS. Um método para análise e co-gestão de coletivos. 2a ed. São Paulo: Hucitec; 2005.

14. Castel R. A gestão dos riscos: da antipsiquiatria à pós-psicanálise. Rio de Janeiro: Francisco Alves; 1987.

15. Foucault M. A história da sexualidade I: a vontade de saber. 17a ed. Rio de Janeiro: Graal; 2006.

16. Lourau R. René Lourau na UERJ - 1993: análise institucional e práticas de pesquisa. Rio de Janeiro: EdUERJ; 1993.

17. Lourau R. A análise institucional. Petrópolis: Vozes; 1975.

18. Bondia JL. Notas sobre a experiência e o saber de experiência. Rev Bras Educ. 2002; 19(1):20-8.

19. Escossia L, Tedesco S. O coletivo de forças como plano da experiência cartográfica. In: Passos E, Kastrup V, Escóssia E, organizadores. Pistas do método da cartografia: pesquisaintervenção e produção de subjetividade. Porto Alegre: Sulina; 2009. p. 92-108.

20. Alvarez J, Passos E. Cartografar é habitar um território existencial. In: Pistas do método da cartografia. Passos E, Kastrup V, Escossia L, organizadores. Porto Alegre: Sulina; 2009. p. 131-49.

21. Kastrup V, Passos E. Cartografar é traçar um plano comum. In: Passos E, Kastrup V, Tedesco S, organizadores. Pistas do método da cartografia: a experiência de pesquisa e o plano comum. Porto Alegre: Sulina; 2014. p. 15-41.

22. Passos E, Barros R. Por uma política da narratividade. In: Passos E, Kastrup V, Escóssia $\mathrm{L}$, organizadores. Pista do método cartográfico: pesquisa-intervenção e produção da subjetividade. Porto Alegre: Sulina; 2009. p. 150-71.

23. Rancière J. A partilha do sensível: estética e política. São Paulo: Ed. 34; 2005. 
24. Onocko-Campos RT, Furtado J. Narrativas: utilização na pesquisa qualitativa em saúde. Rev Saude Publica. 2008; 42(6):1090-6.

25. Rabelo MCM, Alves PCB, Souza IMA. Experiência de doença e narrativa [Internet]. Rio de Janeiro: Fiocruz; 1999 [acesso 2014 Mar 13]. Disponível em: http://books.scielo.org

26. Muñoz N, Serpa Jr O, Leal E, Dahl C, I Oliveira. Pesquisa clínica em saúde mental: o ponto de vista dos usuários sobre a experiência de ouvir vozes. Est Psicol (Natal). 2011; 16(1):83-9.

27. Onocko-Campos RT, Passos E, Palombini A, Santos D, Stefanello S, Gonçalves L, et al. A gestão autônoma da medicação: uma intervenção analisadora de serviços em saúde mental. Cienc Saude Colet. 2013; 18(10):2889-98.

28. Onocko-Campos RT, Passos E, Leal E, Tófoli LF, Serpa O. Pesquisa avaliativa de saúde mental: instrumentos para a qualificação da utilização de psicofármacos e formação de recursos humanos - GAM-BR. Campinas: Universidade Estadual de Campinas; 2008. (Projeto de pesquisa, CNPq).

29. Passos E, Carvalho SV, Maggi PMA. Experiência de autonomia compartilhada na saúde mental: o "manejo cogestivo" na gestão autônoma da medicação. Pesqui Prat Psicossociais. 2012; 7(2):269-78.

30. Benjamin W, organizador. O narrador: considerações sobre a obra de Nikolai Leskov. In: Magia e técnica, arte e política: ensaios sobre literatura e história da cultura. São Paulo: Brasiliense; 1994: p. 197-221.

31. Andrade TM, Lurie P, Medina MG, Anderson K, Dourado I. The opening of South America's first needle exchange program and an epidemic of crack use in Salvador, Bahia-Brazil. Aids Behav. 2001; 5(1):51-64.

Dias RM, Passos E, Silva MMC. Una política de la narratividad: experimentación y cuidado en relatos de reductores de daños de Salvador, Brasil. Interface (Botucatu). 2016; 20(58):549-58.

En este artículo se investiga la política de narratividad vigente en los relatos de campo llevado a cabo por trabajadores de un Programa de Reducción de Daños (PRD) de Salvador en el año 2012. A partir de los diarios de campo, se analizan cuáles son las estrategias narrativas que se engendraron en la práctica diaria de la RD en el campo de la salud pública en Brasil. La evaluación de las narraciones revela una singular experiencia de cuidado con los usuarios de sustâncias psicoactivas en las calles de la ciudad, que se reproduce en el cuidado de su propia experiencia de campo y de investigación. De esta manera surge en las narrativas de reductores de daños una articulación entre la experimentación y el cuidado.

Palabras clave: Reducción de daños. Salud mental. Narrativas. Experimentación. Cuidado. 